\title{
Jóvenes, violencia y medios de comunicación
}

\section{Raúl Zarzuri Cortés}

\section{Resumen}

Este artículo entrega una visión de la relación entre jóvenes, violencia y medios de comunicación. Aborda la construcción de ciertos tipos de jóvenes como "monstruos sociales" y por lo tanto estigmatizados por los medios de comunicación como jóvenes no deseados socialmente por medio del análisis de las movilizaciones de los estudiantes secundarios que tuvieron su auge en la denominada "revolución pinguina", que puso en el tapete de la opinión pública las desigualdades e iniquidades existentes en la educación chilena. Se destaca el rol de los medios de comunicación, particularmente la prensa escrita y la televisión, en la construcción de un imaginario de los jóvenes como "jóvenes violentos", y se realiza un breve ejercicio interpretativo de la violencia juvenil entendida como una "performance" que es utilizada por lo medios para vender y tener rating.

\section{Palabras clave}

Jóvenes y violencia. Medios de comunicación. Violencia preformativa.

\section{Raúl Zarzuri Cortés | rzarzuri@gmail.com}

Sociólogo y Magíster en Antropología por la Universidad de Chile. Investigador del Centro de Estudios Socioculturales - CESC - en el área de estudios culturales y culturas juveniles. Actualmente se desempeña como profesor de la Escuela de Sociología en la Universidad Academia de Humanismo Cristiano.
En nuestra sociedad, la juventud está presente cuando es un problema, o es considerada como un problema. Más precisamente, la categoría "juventud" aparece en el discurso de documentos

oficiales, en editoriales o publicaciones que expresan preocupación, o en supuestos tratados desinteresados emanados de las ciencias sociales en aquellos tiempos donde la gente joven hace sentir su presencia al irse "fuera de los limites": resistiendo a través de rituales, vistiéndose de forma extraña, tomando actitudes bizarras, rompiendo reglas, botellas, ventanas, cabezas, haciendo públicos desafíos retóricos a la ley.

Henry A. Giroux

\section{Antecedentes}

De un tiempo a esta parte, han surgido en nuestro país una serie de cuestionamientos a ciertas manifestaciones juveniles que han venido paulatinamente asomándose y adquiriendo fuerza en nuestras ciudades. De esta forma, ciertas expresiones culturales juveniles que han sido llamadas "tribus urbanas" (por ejemplo: hiphoperos, punkies, dark/góticos, skin-head, etc.) y otras expresiones que se mueven más en el plano de "lo político" - como es el caso de los mal llamados "anarquistas o neo-anarquistas" por la 
prensa - han sido catalogados como situaciones problemas que escapan al control normativo de la sociedad. Por lo tanto, como formas de expresión juvenil, han sido objeto de cuestionamientos, identificándolas como fuente de peligro y riesgo para el orden social con la utilización de rótulos como violentos, delincuentes, drogadictos, entre otras cosas.

Por otra parte, en nuestro país se comenta frecuentemente en los medios de comunicación la importante ausencia de la juventud en el ámbito de la participación y la política. Los jóvenes no se inscriben en los registros electorales, no participan significativamente de la vida político-institucional del país y, por el contrario, el imaginario que circula de algunos jóvenes es que estos aparecen ligados principalmente a grupos vandálicos y a la violencia. Así, muchos jóvenes estigmatizados por su adscripción a una cultura en particular - desconocida y por tanto incomprendida por el mundo adulto - 0 cercanos a ideologías radicales se convierten en noticia toda vez que se relacionan con hechos de violencia. Salvo excepciones, no existe la intención de profundizar en las características socioculturales que se expresan tras estas prácticas. De esta forma, se intentan explicar hechos delictivos a partir de la adscripción a cierta estética particular que marca la diferencia entre los jóvenes que son parte de una tribu o cultura particular y los jóvenes que no pertenecen a ninguna de ellas. Los medios de prensa, perdidos en este mundo de la diversidad cultural juvenil, sólo saben que los llamados "jóvenes tribales" y los "anarquistas" son "antisistémicos", que sus críticas no son conocidas por la mayoría de la población, pero que frecuentemente utilizan la violencia para expresar su rabia y descontento.

De esto se deduce que la construcción de lo juvenil - 0 de un cierto segmento de jóvenes - en nuestro país tiene una fuerte carga negativa, y es un acercamiento que en estos momentos se da marcado por la violencia, lo que en palabras de Jesús Martín-Barbero nos está revelando,

[...]que la preocupación de la sociedad no es tanto por las transformaciones 0 trastornos que la juventud está viviendo, sino más bien por su participación como agente de la inseguridad que vivimos, y por el cuestionamiento que explosivamente hace la juventud de las mentiras que esta sociedad se mete a sí misma para seguir creyendo en una normalidad social que el desconcierto político, la desmoralización y la agresividad expresiva de los jóvenes están desenmascarando. (1998, p. 23)

Por otra parte, habría que señalar que la violencia juvenil es un fenómeno muy complejo y que en estos momentos es objeto de preocupación a nivel societal - en todo el mundo - pero que ha sido simplificado especialmente por los massmedia, los cuales, lejos de contribuir a entender la violencia (para estar en mejores condiciones de enfrentarla), contribuyen a su expansión sin límites visibles y manejables. De esta forma, las respuestas que tradicionalmente se han implementado y que han estado centradas en enfoques puramente represivos no sólo han dado 
pocos resultados, sino que además han provocado el efecto de hacer crecer desmedidamente este problema, cuestión que no ha ayudado a bajar la intensidad de éste. Por otra parte, parece interesante referirse al fenómeno de la violencia no en términos singulares, sino que es más propio de hablar de violencias e incluso, más que hablar de violencias es mejor hablar de manifestaciones de violencia para dar cuenta de una serie de procesos sociales que desembocan en una diversidad de violencias.

Así, se puede destacar una amplia escritura sobre la relación entre jóvenes y violencia, especialmente desde los medios de comunicación, no así desde el ámbito de las ciencias sociales en nuestro país ${ }^{1}$. Sin embargo, este tipo de escritura ha transitado por el camino de la estructuración de un discurso negativo y estigmatizador sobre este tipo de manifestaciones, llevando incluso a la demonización de ciertas prácticas juveniles, donde el uso de la violencia es un recurso más o menos recurrente pero no exclusivo de este segmento de edad. De esta forma, la demonización y el estigma se transforman en la antesala del destierro para un grupo significativo de jóvenes, dado que este concepto es un atributo profundamente desacreditador que hace a sus portadores ser y sentirse extraños a los ojos de quienes se sienten normales; es alguien que no es "apetecible socialmente", lo que puede reducir a una persona - en este caso los jóvenes - a un ser menospreciado, profundamente desacreditado. La opinión pública y principalmente los mass media, en un contexto de alarma social e insegurización permanente, tienden a atribuir a ciertas grupalidades juveniles todos los males sociales de los cuales la sociedad intenta alejarse (ABARCA; SEPÚLVEDA, 2005). Por otra parte, podemos decir que el mundo adulto tiene ciertas obsesiones con los jóvenes que denotan una cierta miopía e hipocresía, ya que precisamente ellos (la sociedad) no son capaces de darse cuenta que el problema no está tanto en los jóvenes, sino en la sociedad que se ha construido. Por lo tanto, como lo señala Jesús Martín Barbero, los jóvenes "están haciendo visible lo que desde hace tiempo se ha venido pudriendo en la familia, en la escuela, en la política" (1998, p. 23).

Frente a todo lo que se ha descrito anteriormente, solamente cabría la posibilidad de una sola forma de entender a los jóvenes: la mirada de la violencia, cuestión que no es así. De esta manera, habría que señalar que los jóvenes de hoy son muy activos y diversos, y no pueden ser clasificados sólo bajo el rótulo de la violencia. Proliferan las organizaciones juveniles de diverso cuño, promoviendo iniciativas y creando vivencias de comunidad joven novedosas y sobretodo diferentes. Ya sea como okupa, gótico, rapero,

Hay que señalar que en una rápida revisión por Internet en las principales bibliotecas de universidades y centros de investigación y estudios no fue posible encontrar estudios que relacionaran la violencia juvenil con la política. En general, se puede encontrar una abundante bibliografía sobre la violencia juvenil relacionada con la delincuencia y la seguridad ciudadana. 
punk, malabarista 2 , "garrero"3 0 como miembro de algún colectivo universitario o como joven realizando actividades de voluntariado, los jóvenes se organizan, construyen identidad y participan de su sociedad, transformándola poco a poco, constituyéndose en uno de los principales motores del cambio cultural.

Hay que señalar también que las organizaciones gubernamentales, a través de sus instancias orientadas a la creación de políticas juveniles, han iniciado un proceso tendiente a lograr un mayor conocimiento de estos fenómenos. Sin embargo, el análisis acerca de lo juvenil se ha centrado generalmente en el discurso sobre la integración, sin tomar en cuenta la especificidad en los modos de ser joven. Tal como plantea Pérez Islas (1998), desde la institucionalidad solo se piensa en los jóvenes cuando tensionan el orden hegemónico. En otras palabras, cuando sus manifestaciones, prácticas y expresiones no se hallan dentro de los cánones que desde la institucionalidad se han establecido como 'normales', por lo que se los define en la mayoría de los casos como anómicos, rebeldes, delincuentes, contestatarios.

Es así como desde una mirada normativa hegemónica, ciertas expresiones juveniles en muchos casos asociadas a expresiones de violencia y también culturales (tribus urbanas) han sido caracterizadas como anómicas, siendo tema de preocupación para los distintos sectores de nuestra sociedad, en tanto formas de expresión juvenil que escapan al control normativo. En ese sentido, concordamos con aquellos autores que han dado cuenta de una suerte de criminalización de estos grupos, planteando la necesidad de mirar también aquellos aspectos que desde lo cultural ${ }^{4}$ son expresivos de una construcción identitaria, en tanto ellos indican configuraciones 0 modalidades a través de las cuales se sitúan como sujetos juveniles.

No está demás señalar que este tipo de visiones negativas sobre los jóvenes ha sido puesto en cuestionamiento, aunque no con la fuerza suficiente todavía. De esta forma, es posible encontrar en un texto que data de 1991, escrito por José Weinstein (ex Ministro de Cultura) - en ese tiempo "experto en juventud" - titulado: "Jóvenes de los '90: ¿"inmorales", "incultos", "apolíticos" 0... "nuevos ciudadanos"?, en el cual daba cuenta de ciertas imágenes estereotipadas negativas que la sociedad y en especial los medios de comunicación utilizaban

Práctica callejera que proviene de las actividades de circo y que requiere de juegos de manos, equilibrio, etc., lo cual exige destreza y agilidad.

Jóvenes que militan en una barra de algún equipo de fútbol.

De acuerdo a N. García Canclini, lo cultural hace referencia al ámbito de la producción, circulación y consumo de significaciones (J. Pérez Islas, en H. Cubides y otros, 1998). En esa misma línea, entenderemos por cultura, "la trama de significaciones en la que el hombre conforma y desarrolla su conducta". (C. GEERTZ, 1996) 
para describir un fenómeno en emergencia, en este caso los jóvenes. Las conclusiones de Weinstein eran que no se pueden aplicar estas imágenes a los jóvenes y que había que realizar un giro, intentando visualizar que hay de nuevo y contributivo en estos, evitando, así, realizar lecturas nostálgicas, para pasar a lecturas más optimistas. De más está decir que han pasado 17 años y todavía esos mismos estereotipos se pueden aplicar, y es más: se podrían agregar otros que son utilizados constantemente, lo cual nos indica que nada ha cambiado respecto de las percepciones que tienen ciertos sectores de la sociedad sobre los jóvenes.

Esto nos indica que debemos cambiar nuestro marco de referencia para aproximarnos a los jóvenes y a la violencia juvenil, planteándonos un desafío epistemológico que ha comenzado a asumirse en las ciencias sociales y humanas por medio de un progresivo cambio de enfoque. Es así como en los últimos años la cultura se ha convertido en el ámbito explicativo más certero para aproximarse a las nuevas realidades sociales de comienzos del siglo XXI, anunciándose como la llave para la comprensión de una realidad plural, dinámica y compleja como la juventud actual. Así, lo que deberíamos preguntarnos, más que estigmatizar, caricaturizar o ridiculizar, es qué se esconde detrás de estas manifestaciones de los jóvenes; qué nos quieren decir. Sin embargo, esto no es tan sencillo, ya que implica dar un giro en la mirada del observador, que tiene que dejar de lado, una mirada externa, donde esta mirada refleja una forma de interpretación constructora de una sola verdad y conocimiento, y pasar al punto de vista del observado, y tratar de comprender e interpretar desde este sujeto, las construcciones y significados que hacen de sus acciones, de su vida. En el fondo, situarnos en lo que Rossana Reguillo (2000) llama una epistemología del encantamiento - donde se reconoce con respeto la condición y calidad de sujetos a los jóvenes y sus manifestaciones culturales - y abandonar una epistemología de la distancia.

\subsection{Para entender a los jóvenes: breves apuntes}

Está claro que hoy en día vivimos en un espacio sociocultural distinto - producto de la emergencia de las nuevas Tecnologías de la Información y Comunicación (TIC's) que da origen a una nueva era en nuestras sociedades, que puede ser leído en clave de "mutación cultural" (BAJOIT, 2003). En esta era, la cultura, lo social, lo político - por señalar algunas dimensiones - mutan, se transforman, posibilitando así a la emergencia de un nuevo tiempo que se caracteriza más por sus incertezas que sus certezas, lo cual deviene en incógnitas de futuro, construyendo un tiempo y mundo que se identifica con las crisis y el desencantamiento con muchas cosas (la política, la educación, etc.). Por otro lado, se instala como una de las cuestiones centrales para entender este nuevo tiempo la idea de que el proceso modernizador se visualiza como un espacio de 
cambio simbólico y cultural más que material (HABERMAS, 1991; TOURAINE, 1995 Y 1996; MELUCCCI, 1999), y como bien apunta Mardones (1988), con esto no se está negando la existencia de desigualdades e injusticias sociales, sino que hay un desplazamiento del núcleo central de las contradicciones sociales. Por lo tanto, Mardones -siguiendo a Touraine y Habermas-, señalará que, "lo puesto en cuestión es el control de los modelos culturales, allí donde se juega la identidad personal y el sentido de la vida." (1988, p. 20)

Este nuevo contexto, posibilita la construcción de sujetos distintos, situación que se radicaliza en los jóvenes, los cuales tienen "una carta" más amplia sobre la cual construir sus identidades (LIPOVESKY, 2000) porque, precisamente en estos contextos de crisis, los dadores de sentido tradicionales (los institucionales como la escuela, la familia, la iglesia, el partido político) comienzan a perder espacio, posibilitando un tipo de construcción identitaria que se caracteriza por realizarse a la intemperie 0 hacerlo a través de otros tipos de sociabilidad más culturales (tribus, barras, grupos de juego, entre otros) - cuestión que hace ver a estas identidades como más precarias, fragmentadas.

Todo este nuevo contexto posibilita la aparición de un sujeto juvenil distinto; podríamos decir, de un sujeto generacionalmente distinto que viene a colonizar un mundo nuevo que se ha construido, producto de todos estos cambios y donde ya no vale ese viejo dicho que los adultos solían decirles a los jóvenes “ssabes una cosa? Yo he sido joven y tú nunca has sido viejo", porque, en estos momentos, los jóvenes pueden responder a estos adultos diciendo: "tú nunca has sido joven en el mundo en el que soy joven yo, y jamás podrás serlo." Esto estaría dando origen a un proceso de división entre generaciones, que podríamos llamar de ruptura generacional.

Brevemente hay que señalar que el uso de la palabra generación remite a una cierta condición etaria que se articula y es procesada con fenómenos culturales e históricos. Así, es posible señalar que cada generación puede ser considerada como adscrita a una cultura diferente, ya que precisamente esta entrega códigos, destrezas, lenguajes y socializaciones, pero que son distintas de generación en generación. Esto permite señalar que ser joven no depende sólo de la edad, ni tampoco del sector social al que pertenece el joven (la clase social), sino que también hay que considerar lo que Margulis (1996) llama el "hecho generacional", "la circunstancia cultural que emana de ser socializado con códigos diferentes, de incorporar nuevos modos de percibir y de apreciar, de ser competente en nuevos hábitos y destrezas, elementos que distancian a los recién llegados del mundo de las generaciones más antiguas."(1996, p. 19). Así, ser integrante de una generación más joven, señala Margulis (1996; 1998; 2003), implica diferencias en el campo de la memoria - no se comparte la misma memoria -, en las experiencias vividas, la historia 
y las formas de percibir el mundo, distinciones entonces que llevan a construcción de mundos y estructuraciones de sentidos diferentes, de acuerdo a la generación que se pertenece.

Se asiste entonces a la construcción de un sujeto que se predica desde la pluralidad más que de la singularidad, por lo tanto no se puede hablar del "joven" ni de la "juventud", sino de los "jóvenes" y de las "juventudes", cuestión que es descrita bastante bien por Rossana Reguillo, al señalar que

[...]en ninguna parte del mundo la juventud representa un bloque homogéneo que pueda hoy en día hacerse caber en un conjunto de categorías fijas. Al igual que otros segmentos de la población, los jóvenes constituyen grupalidades diferenciales, adscripciones identitarias que se definen y organizan en torno a banderas, objetos, creencias, estéticas y consumos culturales que varían de acuerdo al nivel socioeconómico, a las regiones, al grado de escolaridad, entre otros factores que la investigación empírica apenas comienza a desentrañar." (1996, p. 58)

\section{Algunos ejes comprensivos de las Ilamadas "violencias juveniles"}

\section{La naturaleza arma a la juventud para el conflicto con todos sus recursos a su alcance-velocidad, poder de hombros, biceps, espalda, piernas, mandibulas- reforzando y alargando el cráneo, tórax y cintura, lo que hace al hombre más agresivo y prepara a la mujer a la maternidad. .}

Stanley G. Hall, Adolescence, 1905

Una primera pregunta que surge es si es tan natural la relación jóvenes y violencia como aparece señalada por los medios de comunicación o si esta relación es producto de una construcción que se ha naturalizado. Esta pregunta nos sitúa en los orígenes de lo que podemos entender por jóvenes 0 inicialmente por adolescencia. Brevemente hay que señalar que en la literatura - especialmente norteamericana - la categoría psicológica de adolescencia se construyó a partir de una definición que caracterizaba un tiempo especifico dentro del ámbito del desarrollo humano, identificada por ser una edad conflictiva la cual se equiparaba en términos de registro evolutivo de los seres humanos a la prehistoria, marcada por la crisis de identidad y que se manifestaba por las conductas agresivas y violentas propias de seres primitivos no civilizados. Como señalan Ferrándiz y Feixa (2005, p. 210-211) respecto de esta definición acuñada por Stanley G. Hall a principios del siglo XX, de base darwinista,

[...]la adolescencia corresponde a una antigua fase de barbarie por la que pasó la especie humana, previa a la civilización (la inevitable sedentarización que vendrá con la vida adulta).... [de esta forma] las patologías personales expresadas en comportamientos neuróticos, autolesiones, tatuajes, toxicomanías y suicidios (reconstruidas por las variadas tendencias de la psicología desde el psicoanálisis al conductismo) se corresponderían con patologías sociales expresadas en comportamientos agresivos, bandas gregarias, peleas, delincuencia (analizadas por las variadas tendencias de la sociología desde la Escuela de Chicago a la de Birmingham). De este modo no sólo se naturalizó la juventud, sino también la violencia (que aparecía como el resultado lógico e inevitable de determinados factores psicológicos, ecológicos y sociales). 
Demás está decir que esta idea de una

adolescencia (o juventud) conflictiva es puesta en entredicho. Otros estudios de carácter antropológico comienzan a señalar que al parecer la forma en que se manifestaba esta etapa y a la que se le atribuía la agresión y la violencia como características centrales, era más propio de las sociedades occidentales, y no así de otros tipos de sociedad, como las que estudiaría Margared Mead en su inserción en Samoa Occidental y posteriormente en Papua, Nueva Guinea. Las observaciones de esta autora, muestran que el tránsito de los/las llamados/as adolescentes a la vida adulta, no tenía nada de conflictivo, por lo menos en las categorías expresadas por Hall y desarrolladas posteriormente por sus seguidores, introduciendo así, la idea de que estos procesos pueden estar definidos y asumir características en función del entorno cultural en donde se realiza el desarrollo de estos adolescentes, por lo tanto, la adolescencia se definía de acuerdo a necesidades específicas de las culturas en las cuales se insertaba. Sin embargo, a pesar de estos matices, "el daño" ya estaba hecho, se había naturalizado la juventud y también se había naturalizado la relación entre los jóvenes y la violencia, pero también se había introducido un matiz que permitía complejizar esta relación y situarla y/o contextualizarla desde la cultura, cuestión que permitía realizar un ejercicio más compresivo de las relaciones entre jóvenes y violencias.
Si entonces la relación binomial entre jóvenes y violencia es una construcción que se ha naturalizado, la pregunta que surge es cómo se ha producido esa naturalización. Para algunos autores como Jeffey S. Juris (2006), al proceso de naturalización han contribuido poderosamente los medios de comunicación de masas. Hay que entender - como señala Juris - que la violencia es un poderoso icono simbólico que es utilizado por la industria de los medios de comunicación para captar audiencias. En el fondo, se trata de vender o tener más sintonía de público a partir de la construcción de la violencia juvenil por lo menos en dos ámbitos: la construcción de un sujeto joven violento, que tira piedras y/o bombas molotov, que se encapucha y destruye espacios públicos, etc.; y la violencia vista como una "violencia sin sentido". Evidentemente que esta mirada muy superficial de estos fenómenos, de por si complejos, no hace más que construir un imaginario de este tipo de jóvenes como el "nuevo bárbaro o primitivo", que es incivilizado y que atenta contra el orden establecido.

\subsection{La llamada violencia performativa}

Jeffey S. Juris (2005) ha escrito un interesante artículo basado en sus experiencia de trabajo de campo realizado en Génova en el marco de las manifestaciones antiglobalización siguiendo a los militantes .del Black Block (Bloque Negro) que se caracterizaban por las tácticas de acción directa, que este autor llama violencia preformativa. Juris señala respecto 
de la violencia - y citando a Antón Block - que esta no debía ser definida a priori como algo irracional o sin sentido, sino que habría que "considerarla como una forma cambiante de interacción y comunicación, como un patrón cultural de acción significativa históricamente desarrollada." (BLOCK, 2000, p. 24 apud JURIS, 2005, p. 188). Así, Juris ve la violencia como una forma de interacción social mediante la cual se va construyendo realidad con los modelos culturales de los cuales se dispone y, siguiendo a otro autor como Riches (1986 apud JURIS 2006), va a señalar que la violencia se caracteriza por poseer componentes prácticoinstrumentales que intentan modificar el entorno social y componentes simbólicos-expresivos que "enfatizan la comunicación y dramatización de importantes ideas y valores sociales" (JURIS, 2006, p. 188), aunque la diferencia entre estos dos componentes es sólo de grado.

De esta forma, la violencia performativa es vista por Juris como una representación de rituales simbólicos que se manifiestan de forma violenta y que se manifiesta como un mecanismo de comunicación y de expresividad cultural mediante el cual los participantes en estos rituales intentan hacer efectiva la transformación social mediante una confrontación de tipo simbólico que se da en lo que se denomina performances violentos, donde la violencia adquiere dimensiones de espectacularidad icónica y la utilización de un lenguaje no verbal. Así, la violencia performativa es un recurso con que cuentan estos grupos que están limitados en recursos (materiales), lo que habla de una economía de recursos a nivel simbólico (la violencia), que es utilizada dentro de una lucha simbólica. De ahí que la violencia contra ciertos "iconos del sistema capitalista" (bancos, trasnacionales, etc.) sea la forma más llamativa y económica de lograr una victoria a nivel simbólico contra el poder hegemónico y de hacerse visibles mediáticamente, encontrándonos frente a lo que el autor llama "guerras mediáticas de interpretación simbólica", donde los jóvenes

[...] llevan a cabo performances violentas espectaculares, en parte para ganar acceso a los medios de comunicación comerciales, que buscan constantemente historia e imágenes sensacionales. Las formas cotidianas y rutinarias de la protesta no son noticia, mientras que las imágenes icónicas de coches en llamas y batallas callejeras entre manifestantes enmascarados $y$ cuerpos policiales militarizados son retransmitidas al instante a través de las redes globales de comunicación. (JURIS 2006, p. 190).

De esta forma, el acceso a los medios de comunicación es a través de la violencia o el performance violento señalado por Juris, como se aprecia en estas citas,

[...] por lo que te digo, que a veces es la única forma de llamar la atención [la violencia], 0 sea es como la única forma de solucionar. Yo te digo si hací una protesta ciudadana no se pos' se paran puras señoras con carteles de cartulina y no sé, queremos más micros, no sé, no van a pescar, tenis que dejar una caga muy grande para que pesquen, entonces igual están motivando para que halla más violencia porque tampoco reaccionan con protestas ciudadanas, puta juntan firmas y las mandan, tampoco pes- 
can mucho, tiene que quedar la caga para que pesquen, los wueones esperan que les quede la caga y ahí recién escuchan a la gente." (Gabriel, Acción Directa ${ }^{5}$ )

[A raíz de las violencia en la movilización estudiantil del año pasado] Y a mi me sorprendía ver las noticias de todos los canales, nos mostraban todo, las estadísticas de las todas las cagas que habían hecho pero no decían que estaban pidiendo los cabros cachai, hay un morbo, también hay un morbo por la violencia y tampoco buscan porque estaban protestando y al final fue tanto el movimiento que al final salieron los cabros leyendo lo que pedían pero fue una wuea que tardó, que desde el comienzo que empecé a ver en las noticias, los desmanes ese era el tema, los desmanes pero no el tema de las exigencias. (Estudiantes Secundarios, 20076)

De esta forma, se puede ver la violencia como una forma de visibilidad y de presencia en el marco de una cierta ritualidad expresiva en el cual la performance adquiere relevancia. Siguiendo a Rodrigo Díaz (2002) - quien sigue al antropólogo Max Gluckman -, la ritualización puede ser entendida como los comportamientos convencionales y estilizados que segregan y/o se distinguen en un sistema jerárquico de posiciones y relaciones, particularmente en las sociedades simples y también complejas que ayudan a comprender las acciones sociales. Sin embargo, Díaz señala que Gluckman, influenciado por Durkheim, enfatizó demasiado en la estructura de status, posiciones y roles para un desempeño "correcto" en la sociedad (los aspectos normativos/ritualización domesticada) en desmedro de otros usos que tienen las características de ser situacionales y que no están apegados a las normas y reglas (ritualización salvaje), como sería en este caso el uso de la violencia. Un ejemplo menos complejo sería el tatuaje - como señala Díaz -, que segrega pero a la vez identifica e integra, por lo que esta práctica emite muchos mensajes además del simple tatuarse, cuestión que se debe tener en consideración cuando nos enfrentamos al recurso de la violencia por parte de ciertos jóvenes. De este modo, se puede afirmar que el acto de ritualización está "configurado por acciones simbólicas que segregan e integran, que expresan algo y que las interpretaciones posibles de ese algo gestan tensiones, están en conflicto [...]". (DÍAZ, 2002, p. 26).

Así, como señala Díaz, la ritualización se puede ubicar en el ámbito del performance (como uno de sus casos singulares), esto porque los rituales no son solamente redes de acciones simbólicas que emiten mensajes, sino que además son una construcción social de la realidad que nos remite a hábitos y técnicas corporales. Ambos, performance y ritualización, están articulados por la creación de la presencia (recreación y un hacer presentes situaciones ya vividas que pueden reforzar a alterar disposiciones). El performance se puede entender, entonces, como "un hacer que describe ciertas acciones 
que están transcurriendo, ejecutados en sitios específicos, atestiguados por otros o por los mismos celebrantes: es un hacer que focaliza esa presencia en tanto acto de creación [... ]" (DÍAZ, 2002, p. 27), pero es un hacer que también conlleva campos discursivos preexistentes como las convenciones de género, tradiciones, tensiones políticas y sociales, etc. Entonces no es sólo un "repetir", sino que es un repetir en un "presente performativo" que no está cerrado, sino abierto. Por lo tanto, posibilita interpelar esos campos discursivos existentes.

De esta forma, los grupos se van haciendo visibles a través del performance, haciendo y creando un acto de presencia, el cual puede ser entendido también como una "ceremonia definicional", señala Díaz (2002). Así,

[...]la cualidad distintiva de las ceremonias definicionales es que se despliegan ahí donde un grupo, por ejemplo una banda, sufre de crisis de invisibilidad, de inexistencia, de marginalidad, de inferioridad estructural, de dominio y desconocimiento por una sociedad u otro grupo más poderoso. Por eso constituyen estas ceremonias "dramas simbólicos": no son meras representaciones de condiciones y formas de vida, sino que aluden a agentes creativos autoperformativos, que elaboran, organizan y recrean prácticas, discursos, creencias, valores y actitudes, memorias y proyectos políticos y culturales para hacerse visibles y existentes. (DÍAZ, 2002, p. 36)

Entonces, a partir de estos actos performativos ritualizados que (re)crean dramas simbólicos, los jóvenes son capaces de trastocar el orden normativo en el plano cultural-simbólico más que en el político-social, constituyéndose estos actos performativos en una clase de poder; como actos de "reinvocación y resistencia" que apelan a la creación y la imaginación de un futuro deseado. Por lo tanto, dramatizan las identidades de los grupos, por lo que no es posible o no se puede concluir que al realizar estos performances los grupos sean efectivamente así. En el fondo, instalan la necesidad del reconocimiento y del derecho a la diferencia.

\section{La violencia, Ios jóvenes y los medios de comunicación}

Un ejemplo de la relación entre violencia y medios de comunicación es la que existe cuando la televisión y la prensa escrita informan sobre hechos de violencia. En el caso de la televisión, estudios realizados por el Consejo Nacional de Televisión muestran que el tema de la violencia a partir del concepto de seguridad ciudadana asociado a la delincuencia ocupa el segundo lugar en las noticias de los noticiaros nacionales, señalando, además, la "existencia de una tendencia general de incluir el tema de seguridad ciudadana dentro de las 'primeras notas', estructurando así la agenda informativa de los canales." (CNTV, 2002) Este es un indicador interesante a la hora de analizar qué se ve en televisión, más aún considerando que la gente se informa más por este medio que por medios escritos. Entonces, evidentemente, hay una fuerte presencia de la violencia en la televisión. Por otro lado, la prensa escrita ha desarrollado un extraño interés por lo jóvenes, particularmente a partir de su relación con la violencia que no se condice con la cantidad de hechos violentos que cometen los jóvenes, descontando por supuesto los hechos catalogados de delictivos. 
De esta forma, los medios de comunicación - a través de las noticias - son vistos por los jóvenes como creadores de la violencia, en el sentido de que la realzan, la visibilizan, porque es lo único que muestran.

[...] en las noticias se ve po' [la violencia], la hora que dan de noticias, aparte de los comerciales, son 45 , son 40 minutos, 30 minutos de pura violencia del país, 10 minutos de violencia a nivel mundial y 5 minutos que te dan de un recital o de cultura y nada más." (Gabriel, Acción Directa)

Y los medios de comunicación en el mundo entero, lo único que muestran, por lo menos aquí en Chile, del mundo es violencia no muestran otra cosa...las noticias son violentas en todo lados... El mayor porcentaje de cosas que muestran en las noticias del mundo, cachai', que violencia, que Irak, que acá, cachai' y lo único que están mostrando: violencia, violencia, violencia...Es lo único. (Secundarios 2007)

Por otra parte, si se toma el trabajo que realiza el Centro de Estudios Socioculturales (CESC), en relación al seguimiento de noticias escritas para monitorear la forma en que la prensa se aproxima al tema de los jóvenes, se puede señalar que, para el año 2006, de un total de $3377^{7}$ noticias analizadas, se pudo encontrar que solo un 5\% de ellas (171) remitían a situaciones de violencia, lo que es un porcentaje bastante bajo como para atribuir a los jóvenes o catalogarlos de violentos como lo ha hecho la prensa.

Brevemente se puede señalar que las grandes noticias sobre los jóvenes fueron las movilizaciones del denominado "movimiento de los pingüinos", la visibilización de los "grupos neonazis" y la emergencia del joven antisistema identificado con el anarquismo, todas las cuales fueron presentadas con gran espectacularidad desde la lógica de la violencia. Para el caso de la movilización de los estudiantes secundarios, las primeras semanas de cobertura mediática estuvieron marcadas por una presentación de carácter violento, obviando el fondo del asunto: las demandas por una mejor educación, imagen que tuvo que cambiar cuando las manifestaciones fueron ganando simpatía en la población ${ }^{8}$.

EI CESC viene realizando un seguimiento de prensa desde el año 2005, que se muestra a través de un boletín de análisis mensual Ilamado "JÓVENESADIARIO" al cual se puede acceder a través de la página web: www.cesc.cl. Este análisis no es exhaustivo ya que sólo responde a las noticias publicadas en la Región Metropolitana, correspondiente a todos los diarios y revistas que circulan en la región. Sin embargo, es bastante representativo a nivel nacional.

La cobertura de las primeras manifestaciones estudiantiles por parte de los medios de comunicación puso el énfasis en el número de detenidos y en los incidentes "violentos" que se producen en las primeras marchas secundarias. La protesta estudiantil se construyó en la prensa como un conflicto callejero y "vandálico", como espacio de violencia y de desorden y no como expresión válida de un descontento con el sistema educacional. Es más, se intentó restar validez al movimiento publicando frases como "la gran mayoría (de los escolares) desconocía las propuestas que presentarían ante el ministerio" (El Mercurio, 7 abr. 2006). De esta forma, la violencia se convirtió en el hilo conductor de las informaciones publicadas sobre los jóvenes, desde las manifestaciones callejeras, las agresiones y delitos cometidos por los grupos neonazi e incluso la discusión en torno a la puesta en marcha de la ley de responsabilidad penal juvenil. Sin embargo, al avanzar los días, la visión de la prensa comenzó a variar, cuestión que llama la atención para entender cómo en 20 días una protesta pasó de ser un acto vandálico a una expresión válida que logró instalar el debate sobre la educación en Chile y hacer demandas concretas y cambiar la agenda de la presidenta. De hecho, esta situación (de la violencia a la veneración), fue titulada por el sociólogo Antonio Cortés Terzi (2006) en una columna del Diario La Nación: "De la vandalización al apologismo (o el caradurismo nacional)." 
Respecto de la visibilización del movimiento neonazi o skin, estos fueron presentados como ultraviolentos sin hacer distinciones entre los distintos tipo de skin que conforman este universo, alcanzando ribetes de histeria colectiva como también sucedió con los denominados jóvenes "anarquistas o neo anarquistas", dando cuenta de supuestas hordas de sujetos violentos que estaban amenazando la ciudad, transformándola en territorio sin ley, cuestión que tuvo su corolario en la molotov lanzada contra el Palacio de la Moneda en septiembre. Por último, un dato no menor a estas construcciones periodísticas, es lo que ocurrió durante la conmemoración del día del joven combatiente ${ }^{10}$ este año, cuando, con días de anticipación, los medios de comunicación y el gobierno comenzaron a pronosticar un día de extrema violencia, lo que llevó a situaciones apocalípticas, como un centro de Santiago casi vacío o el pánico desatado para retornar temprano a las hogares por parte de la gente. Así, la profecía que había sido profetizada se cumplió.

\section{Un análisis de caso: la movilización de los estudiantes secundarios y la construcción del estigma, de "monstruos sociales" y violentos por parte de la prensa chilena}

A modo de recuento durante el inicio del nuevo siglo respecto de las movilizaciones de los estudiantes secundarios en Chile, hay que señalar que estas comenzaron a gestarse a inicios del año 2000 y que tiene su punto culminante en el año 2006 con una serie de manifestaciones masivas, lo que permite en el imaginario comunicativo acuñar o denominar este proceso de "la revolución de los pingüinos".

Por otra parte, hay que destacar que la actitud de los estudiantes secundarios en el año 2006 demostró a la opinión pública y a las autoridades de gobierno la capacidad organizativa y la elaboración de un diagnóstico bastante certero del estado de la educación en Chile. Este había pasado de ser un problema de "cobertura educacional" a un problema de "calidad de la educación", lo que posibilitó la organización de una serie de demandas por parte de los estudiantes a las autoridades y también a la sociedad chilena en general por cambios de esta

Sobre los neo-anarquistas, por ejemplo, se les identifica como una extraña y heterogénea mezcla de jóvenes provenientes de diversas tribus urbanas, vinculándolos a manifestaciones de anarquismo en la actualidad y con el resurgimiento de grupos antisistema en Sudamérica, los cuales han sido generadores de violencia y, por lo tanto, objeto de atención por parte de los sistemas de seguridad: "En Chile, la policía recién está abocada a investigar más el posible surgimiento de movimientos anarquistas con base política y una postura violentista, ya que hasta ahora se sabe que son grupos que no tienen una orgánica ni líderes conocidos, y sus huestes son una extraña y heterogénea mezcla de jóvenes provenientes de diversas tribus urbanas, entre ellos punks, marginales y barras bravas (EDITORIAL, 2008)."

Día que recuerda el asesinato de los hermanos Vergara Toledo, dos jóvenes que pertenecían al Movimiento de Izquierda Revolucionaria (MIR) de 18 y 20 años, que fueron asesinados por la policía, en el año 2005. Desde ese año, todos los 29 de marzo se realizan actividades conmemorativas por la muerte de estos jóvenes. 
situación, que implicaba la modificación de la Ley Orgánica Constitucional de Educación (LOCE), cuestión que motivó una serie de movilizaciones durante el año 2006.

Habría que decir también que las movilizaciones acaecidas en el año 2006 no tienen parangón respecto de las escasísimas movilizaciones acaecidas desde el año 1990 hasta la fecha ${ }^{11}, 0$ sea, desde la llegada de la democracia al país. Como señalaban algunos medios informativos - avanzadas las manifestaciones (protestas y paros)- más de un millón de personas se movilizó a finales de mayo, continuando con la caracterización de manifestaciones de carácter violento ${ }^{12}$. Hay que señalar que la convocatoria no solo aglutinó a estudiantes, sino también a profesores, apoderados o padres y otros actores, como trabajadores del cobre, de la salud, etc., constituyéndose en una movilización - por lo menos en sus inicios - cada vez más transversalizada a nivel de actores y poniendo una interrogación no solo sobre la educación, sino también sobre el país o la sociedad que se quiere construir.

Esto originó una serie de presiones sobre las autoridades del ministerio de educación, pero también sobre el gobierno, el cual, frente al nivel de las movilizaciones, tuvo que modificar su agenda, integrando obligatoriamente las demandas estudiantiles, pese a que se habían negado inicialmente. Así, se dio origen a la formación del denominado Consejo Asesor Presidencial para la Educación ${ }^{13}$ con representación de secundarios y universitarios, quien tuvo que llevar a cabo el trabajo de presentar una propuesta para modificar la actual ley de educación, lo que bajó la intensidad de las movilizaciones de los estudiantes secundarios. Posteriormente estos se retiraron, dado que el documento final de conclusiones de este organismo, fue considerado poco representativo del sentir de los estudiantes secundarios.

En este ámbito, hay que señalar las movilizaciones en contra del uso de armas nucleares en el Atolón de Mururoa, que congregó en un parque de la ciudad de Santiago a cerca de 12.000 mil personas (septiembre 2005). También está la movilización en contra de la APEC, que congregó a cerca de 60.000 personas (noviembre 2004). Por último, se puede mencionar las movilizaciones en contra del fallo del Tribunal Constitucional que prohibía la entrega de la píldora del día después en instituciones públicas, que reunió cerca de 12.000 personas (abril 2008).

El 6 de mayo, La Tercera, La Nación, El Mercurio y La Hora, informaron de los resultados del llamado a paro. Hubo más de 200 detenidos, saqueos y desmanes. Algunos titulares que describieron la jornada:

- "Desmanes y saqueos marcan paro nacional de alumnos secundarios", La Tercera, 6 de mayo

- "El paro nacional fue más estudiantil que social", La Nación, 6 de mayo.

- "Saqueos y violencia marcaron paro nacional de secundarios", La Hora, 6 de mayo.

13 Este consejo estuvo compuesto por 74 personas entre especialistas del área, técnicos, docentes y representantes estudiantiles. Estos últimos eran sólo 12, la mitad lo constituían estudiantes secundarios y la otra estudiantes universitarios de universidades públicas y privadas. Los principales temas que abordaron fueron la institucionalidad de la educación, considerando que este ha sido el aspecto menos trabajado durante los últimos 16 años, además de la revisión de la Ley Orgánica Constitucional de Enseñanza, para hacerle los cambios correspondientes para asegurar que las exigencias realizadas a los establecimientos y a los sostenedores sean suficientes para producir calidad y equidad en este ámbito. Esta comisión evacuó un informe a finales del 2006. 
Durante el año 2007, las movilizaciones fueron escasas a pesar de las críticas que se mantenían al sistema educativo y particularmente a los resultados que se habían llegado con el consejo asesor. Quizás una de las posibles explicaciones - claro está que no es la única - sea la entrada en vigencia de la nueva Ley de Responsabilidad Penal Juvenil, que fue presentada como ley en el año 2000. Julio Cortés ${ }^{14}$ nos recuerda que la presentación de este proyecto de ley en el año 2002 se produce contemporáneamente a las primeras movilizaciones secundarias contra el pase escolar que corresponden a uno de los antecedentes de la rebelión estudiantil del año 2006. En esta época el "vandalismo" y los actos delictivos de estos jóvenes son lo destacado en la primera plana de algunos periódicos.

Respecto de la gran movilización ocurrida en el año 2006, hay que señalar que los medios los medios de comunicación que comenzaron a cubrir las movilizaciones de los estudiantes secundarios que perseguían el cambio de la antigua ley de educación, inicialmente pusieron el énfasis en el número de detenidos ${ }^{15}$ y en los incidentes "violentos" que se produjeron en las primeras marchas secundarias. De esta forma, la protesta estudiantil se construyó en la prensa como un conflicto callejero y "vandálico", como espacio de violencia y de desorden y no como expresión válida contra un sistema educacional que legitima la segmentación de clase y que distribuye diferencialmente la calidad de la educación de acuerdo a los ingresos, no posibilitando la movilidad social, cuestión promocionada y validada por el gobierno y ciertos sectores de la sociedad.

Así, los medios de comunicación, comenzaron a cubrir las primeras manifestaciones estudiantiles dentro del denominado marco de la "violencia estudiantil". Saqueos, desmanes

14 Abogado de un organismo NO Gubernamental dedicado al trabajo con menores Ilamado OPCION, y parte del equipo del Observatorio de Justicia Juvenil del Centro de Estudios Socio-Culturales (CESC).

15 Estos movilizaciones de estudiantes fueron altamente masivas al contrario de lo que ocurre con otros actores movilizados (trabajadores subcontratados, pescadores, etc.). Por lo tanto, respecto del "volúmenes de detenciones", estos son mucho más grandes, tal como se puede apreciar a modo de ejemplo en el siguiente cuadro.

Detenciones de estudiantes en algunas movilizaciones estudiantiles

\begin{tabular}{|c|c|c|}
\hline $\mathbf{N}^{0}$ detenidos & Lugar & Fecha \\
\hline 280 & Nacional & Abril 2008 \\
\hline 530 & R. M & Abril 2008 \\
\hline 200 & R. M & Junio 2007 \\
\hline 26 & R. M & Octubre 2006 \\
\hline 86 & R. M. & Septiembre 2006 \\
\hline 110 & Maipú & Agosto 2006 \\
\hline 4.425 & Nacional & Mayo 2006 \\
\hline 956 & Concepción/ R. M. & Abril 2006 \\
\hline Total: 6.613 & \multicolumn{2}{c}{} \\
\cline { 1 - 3 }
\end{tabular}


y enfrentamientos con la policía fueron las imágenes que se mostraron a los lectores 0 televidentes, cuestión que ponía en segundo plano las demandas estudiantiles.

- "Violentos incidentes entre escolares y carabineros", Publimetro, 27 de abril.

• "El rock del peñascazo fue hit en la Alameda", La Cuarta, 28 de abril.

• "Secundarios volvieron a las calles", Diario Siete, 5 de mayo.

• "Violencia callejera marcó la jornada", $E l$ Mercurio, 6 de junio.

- "Movilización estudiantil culmina con incidentes, destrozos y heridos", La Tercera, 6 de junio.

De esta forma, la prensa tanto escrita como televisiva, intentó restar validez al movimiento publicando frases como "la gran mayoría (de los escolares) desconocía las propuestas que presentarían ante el ministerio" 0 centrándose - como ya señalamos - en la violencia que se convirtió en el hilo conductor de las informaciones publicadas sobre los jóvenes. Tampoco las autoridades de gobierno estuvieron ajenas a esto, dado que, al inicio de estas movilizaciones, las autoridades intentaron bajar el perfil a estas demandas, tratando de construir una imagen de niños chicos, infantilizándolos y tratándolos de poco maduros, por lo tanto, considerados como no actores, no sujetos y poco dignos de ser considerados en las conversaciones sobre los problemas nacionales.

Sin embargo, al avanzar los días y semanas, la visión de la prensa tuvo que comenzar a variar, dando un giro en sus pautas informativas cuestión que llama la atención para entender cómo, en un lapso corto de tiempo, una protesta catalogada como un acto vandálico pasó a ser considerada como una expresión válida casi de veneración por estos jóvenes que lograron instalar el debate sobre la educación en Chile, hacer demandas concretas y cambiar la agenda de la presidenta Bachelet. Así, se pasó del estigma a la veneración de las movilizaciones, cuestión que un columnista de la prensa escrita tituló en un artículo De la vandalización al apologismo (o el caradurismo nacional). Lo que el autor quería mostrar e intentar explicar era cómo se pasó de la imagen de jóvenes violentos a jóvenes reflexivos, capaces de remecer al país y cambiar la agenda de la política y la política educacional en tan corto plazo. Así, el sociólogo y columnista del diario La Tercera Antonio Cortés Terzi culpará a la televisión de construir una imagen negativa al inicio del movimiento.

Estos ejemplos que hemos señalado nos indican algunas cosas interesantes al momento de analizar la relación entre medios, jóvenes y violencia. Como señala Juris (2005), la violencia es un extraordinario icono simbólico, José Antononioutilizado tanto por lo jóvenes como por los medios de comunicación. Estos 
últimos, nos dice el autor, utilizan la violencia para captar audiencias o como señala Juris leyendo a Glitin (1980) y Hall (1974). Las imágenes de confrontación violenta utilizadas por los medios sirven para descontextualizar las performances violentas y reinsertar estas en ciertas narrativas hegemónicas que lo único que hacen es marginalizar, en este caso a los jóvenes, pero también a otros actores, como criminales y desviados, posibilitando así la realización de un ejercicio reinterpretativo de la violencia, donde esta es leída como una "violencia sin sentido", por lo que siguiendo a Juris, los medios actúan de cierta forma como filtros ideológicos al servicio de la hegemonía dominante. Por otro lado, el decaimiento de las noticias sobre la violencia demanda hechos más violentos y espectaculares, constituyéndose así un círculo vicioso que no tiene fin, donde los medios demandan cada vez más violencia para poder vender y alcanzar altas sintonías, cuestión que se puede apreciar en las siguientes citas de estudiantes.

[la violencia se utiliza] [...] para llamar la atención yo creo. Porque en las primeras protestas nosotros nos pudimos dar cuenta que en una marcha pacífica, igual sale en los medios, sale en los medios pero como que no pescan mucho, pero cuando se ve que los estudiantes 0 las personas que están marchando son más violentas, eso como que llama la atención [...] yo vivo hace 3 años en Maipú, mira, no sé, con la Coordinadora de secundarios de Maipú, que ya se disolvió hace rato ya, pero sacamos dos marchas pacíficas, super pacíficas, o sea, nos sentamos en la calle a lo más 5 minutos pa' llamar la atención un rato y después ya, todos pa' la casa, cuando llegué a la casa y prendí la tele, no llegó prensa, no llegó nada...Pero en cambio sali' a la Plaza de Maipú y haci' mierda la Plaza de Maipú, estai' 6 horas combatiendo con los pacos y sale dos días en la tele...Y en todos es igual. [...] Lo que nos pasó a nosotros es que fuimos nos sentamos en la calle, qué pasó, no llegó, iba a llegar la prensa, todo, cuando ya había quedao' la tremenda embarra.." (Estudiantes Secundarios 2007)

Ya había pasado todo, pero después de que pasó la embarra' llegaron [la prensa], cachai', en el momento en que estaban todos sentados en Avenida Larrain, nadie llegó. (Estudiantes Secundarios, 2007)

De esta forma, la visibilización de la violencia por parte de los medios y sus asociados (delito, delincuencia, crimen, etc.) no hace otra cosa que objetivar el miedo en la sociedad, el cual "se proyecta en una minoría, la de los portadores del miedo y la sospecha" (BONILLA; TAMAYO, 2007). Asistimos entonces a la construcción de una otredad que es vista primero como extraña y después como monstruosa, desatando una ola de "pánico moral", particularmente porque el miedo a ese otro (los jóvenes violentos) es un miedo por no poder controlar a una otredad, o sea, se le teme a aquello que no se puede controlar, lo cual siguiendo a Baumann (2001) - quien sigue a Lévi Strauss - implica la adopción de tres posibles estrategias: la primera es la asimilación, o sea, el aniquilamiento del otro como otredad; la segunda es la expulsión, propio del vomitar a las otredades rebeldes, por lo tanto incomunicarlas y excluirlas; y, por último, simplemente la eliminación. Todo esto nos lleva, como Bonilla y Tamayo (2007) nos señalan, a una "criminalización mediática" de cierto tipo de jóvenes. 
Es importante recordar que, más allá de que efectivamente algunos secundarios protagonizaron hechos de violencia, el año 2002 fue la primera vez en mucho tiempo en que los secundarios se manifestaban en masa en las calles de Santiago con demandas bien particulares, lo cual también constituía un hecho noticioso digno de destacar. Así, paradojalmente, un actor minusvalorado por la sociedad chilena; un actor secundario, que en términos estrictos no es un ciudadano pleno; que está en términos biológicos entrando a la juventud (adolescencia para otros) o ya está en esta etapa, o sea, a medio camino de la adultez, lleva adelante una serie de movilizaciones con sentido de país, criticando fuertemente el sistema educacional imperante bajo una lógica de libre mercado. Pero una de las particularidades de estas movilizaciones es que supuso la convergencia con otros actores: profesores, apoderados, trabajadores, convirtiendo las movilizaciones en una cuestión inédita y trasversal a la sociedad chilena.

\section{A modo de conclusión}

Se puede concluir que hablar de la violencia no es nada de sencillo, definirla tampoco. Por otro lado, la violencia en la sociedad siempre ha existido, por lo que es difícil afirmar si hoy en día existe más violencia o no. Al parecer, sí se puede señalar que la violencia hoy en día asume diversas caras, o sea, han cambiado sus manifestaciones.

En esta misma línea, la Organización Mundial para la Salud (OMS) señala, en un informe evacuado el año 2003, que las expresiones de violencia son múltiples y que estas realidades requieren ser abordadas de manera multidimensional, y por sobre todo como un asunto de salud pública, donde deben estar todos los actores sociales (estado, autoridades locales, policías, sociedad civil, etc.) involucrados y comprometidos de manera activa en la búsqueda de soluciones eficaces e integrales para superar este problema.

En ese sentido, hay que destacar - a partir de dicho informe - que una de las formas de violencia más visible en la sociedad resulta ser la violencia juvenil. Es así que en casi todos los países son los adolescentes y los adultos-jóvenes las principales víctimas y perpetradores de dicha violencia. Por otra parte, la violencia juvenil daña profundamente no sólo a las víctimas, sino también a sus familias, amigos y comunidades en general. Este tipo de violencia provoca un fuerte deterioro de la calidad de vida de quienes se encuentran expuestos cotidianamente a sus efectos; un incremento de los costos de los servicios de salud; una reducción de la productividad; una disminución del valor de la propiedad; y en general una desorganización de los servicios esenciales, socavando - a veces- la estructura misma de la comunidad.

De tal manera, no es posible considerar el problema de la violencia juvenil aislado de otros comportamientos problemáticos, como por ejemplo: la deserción escolar, el abuso 
de sustancias psicotrópicas, la violencia intrafamiliar, el maltrato infantil, etc. Abordaje que necesariamente debe considerar no sólo factores cognoscitivos, sino sociales, comportamentales, $\mathrm{y}$ - por cierto - a los propios sistemas sociales que configuran esos factores.

Por otra parte, Ramos, González y Bolaños (2002), señalan siguiendo a Sellers (1995) que los jóvenes viven en un sistema legal, social y político que es muy restringido culturalmente, donde precisamente la imagen que se tiene de ellos es que no son suficientemente capaces de administrar su vida. Por lo tanto, gozan de pocas libertades y recursos, lo que lleva a un cierto malestar entre los jóvenes que puede desencadenar en hechos violentos que paradojalmente van a ser utilizados para tratarlos con menos respeto y más castigo.

Como se puede apreciar, la violencia es un concepto polisémico al igual que la juventud 0 los jóvenes, por lo que, al hablar de violencia hay que realizar distinciones, lo que lleva a pluralizar el concepto, pasando de la violencias a las violencias, como única forma de entender este fenómeno.

\section{Referencias bibliográficas}

ABARCA, Humberto; SEPÚLVEDA, Mauricio. Barras bravas, pasión guerrera. Territorio, masculinidad y violencia en el fútbol chileno. In: FERRÁNDIZ, Francisco; FEIXA, Carles. Jóvenes sin tregua: culturas y políticas de la violencia. Barcelona: Antropos, 2005.
BAJOIT, Guy. Todo cambia: análisis sociológico del cambio social y cultural en las sociedades contemporáneas. Santiago de Chile: LOM, 2003.

BAUMANN, Zigmunt. La posmodernidad y sus descontentos. Akal Ediciones S.A., Madrid España, 2001. BONILLA, Jorge Iván; TAMAYO, Camilo Andrés. Las violencias en los medios, los medios en las violencias: revisión y análisis crítico de los estudios sobre medios de comunicación y violencia en América Latina 1998 - 2005. Bogotá.: Centro de Investigación y Educación Popular -Cinep; Pontificia Universidad Javeriana, Universidad Eafit; COLCIENCIAS, 2006.

CONSEJO NACIONAL DE TELEVISIÓN (CNTV).

Barómetro de la violencia, n. 2, Santiago de Chile 2002.

CUBIDES, Humberto; LAVARDE, María Cristina; VALDERRAMA, Carlos. Viviendo a toda" Jóvenes, territorios culturales y nuevas sensibilidades. Santafé de Bogotá: Universidad Central-DIUC, 1998.

DÍAZ Cruz, Rodrigo. La creación de la presencia: simbolismo y performance en grupos juveniles. In: NATERAS, Alfredo. Jóvenes, culturas e identidades urbanas. México: Universidad Autónoma Metropolitana, 2002.

FERRÁNDIZ, Francisco; FEIXA, Carles. Jóvenes sin tregua. Culturas y políticas de la violencia. Antropos Editorial, Barcelona: Antropos, 2005.

GEERTZ, Clifford. La interpretación de las culturas. Barcelona: Paidós, 1973.

GIROUX, Henry A. Doing cultural studies: youth and the politics of neoliberalism, Harvard

Educational Review, [S.I.], n. 64, vol. 3, p. 278-308, fall 1994. Disponible en: <http://www.henryagiroux. com/Youth_PolOfNeolib.htm>.Acceso en: $10 \mathrm{de}$ Junio 2007.

HABERMAS, Jürgen. El discurso filosófico de la modernidad. Madrid: Teknos, 1991 
JURIS, Jeffrey S. Violencia representada e imaginada: jóvenes activistas, el Black Bloc y los medios de comunicación en Génova. In: FERRANDIZ, Francisco; FEIXA, Carles. Jóvenes sin tregua.

Culturas y políticas de la violencia. Barcelona: Antropos, 2005.

LYPOVETSKY, Gilles. La era del vacío: ensayo sobre el individualismo contemporáneo. 13. ed. Barcelona: Anagrama, 2000.

MARDONES, José. Postmodernidad y cristianismo.

El desafío del fragmento. Maliaño, España: Sal Terrae, 1988.

MARTÍN-BARBERO, Jesús. Jóvenes: des-orden cultural y palimsestos de identidad. In: CUBIDES, Humberto; LAVARDE, María Cristina; VALDERRAMA, Carlos. "Viviendo a toda": jóvenes, territorios culturales y nuevas sensibilidades. Santafé de Bogotá: Universidad Central-DIUC, 1998.

MARGULIS, Mario. La juventud es más que una palabra. In: (ed.). La juventud es más que una palabra. Buenos Aires: Biblos, 1996.

La construcción social de la condición de juventud. In: In: CUBIDES, Humberto; LAVARDE, María Cristina; VALDERRAMA, Carlos. "Viviendo a toda": jóvenes, territorios culturales y nuevas sensibilidades. Santafé de Bogotá: Universidad Central-DIUC, 1998.

(ed.). Juventud, cultura, sexualidad: la dimensión cultural en la afectividad y la sexualidad de los jóvenes de Buenos Aires. Buenos Aires: Biblos, 2003.

(ed.). Juventud, cultura, sexualidad. La dimensión cultural en la afectividad y la sexualidad de los jóvenes de Buenos Aires. Buenos Aires: Biblos, 2003.

MEAD, Margaret. Cultura y Compromiso. Estudio sobre la ruptura generacional. Buenos Aires: Granica, 1971.
MELUCCI, Alberto. Acción colectiva, vida cotidiana y democracia. México: El Colegio de México; Centro de Estudios Sociológicos, 1999.

\section{ORGANIZACIÓN MUNDIAL DE LA SALUD. Informe}

Mundial sobre Violencia. OMS, 2003

PÉREZ ISLAS, José Antonio. Memorias y olvidos: una revisión sobre el vínculo de lo cultural y lo juvenil. In: CUBIDES, Humberto; LAVARDE, María Cristina; VALDERRAMA, Carlos. "Viviendo a toda": jóvenes, territorios culturales y nuevas sensibilidades. Santafé de Bogotá: Universidad Central-DIUC, 1998.

RAMOS, Luciana; GONZÁLEZ; Catalina; BOLAÑOS, Fernando. Juventud, género y violencia. In: NATERAS, Alfredo. Jóvenes, culturas e identidades urbanas. México D. F.: Universidad Autónoma Metrpolitana, 2002.

REGUILLO, Rossana. Ensayo(s) sobre la(s) violencia(s): breve agenda para la discusión, Bogotá, Siglo y Pensamiento, n. 29, p. 9-18, 1996.

Emergencia de culturas juveniles: estrategias del desencanto. Buenos Aires: Norma, 2000.

TOURAINE, Alain. Producción de la sociedad.

México: Universidad Nacional Autónoma de México; Instituto de Investigaciones Sociales; Instituto Francés de América Latina, 1995.

Podremos vivir juntos: iguales y diferentes. México: FCE, 1996.

WEINSTEIN, J. "Jóvenes de los 90": ¿"inmorales", "incultos", apolíticos" 0... "nuevos ciudadanos"? Santiago de Chile: CIDE, 1990. (Documento n. 3)

ZARZURI, Raúl; GANTER, Rodrigo (eds.). Jóvenes la Diferencia como Consigna. Ensayos sobre la diversidad cultural juvenil. Santiago de Chile: Centro de Estudios Socioculturales (CESC), 2005. 
_ Culturas juveniles, narrativas

minoritarias y estéticas del descontento. Santiago de

Chile: Ediciones Universidad Católica Cardenal Raúl

Silva Henríquez, 2002.

\section{Articulos de prensa}

TERZI Cortés, Antonio. De la vandalización al

apologismo (o el "caradurismo" nacional), La Nación,

Santiago de Chile, 6 jun. 2006 .

EDITORIAL, La Segunda, Santiago de Chile, 27 dmar.

2008. 
Youngsters, violence and means of communication

\section{Abstract}

This article presents an account on the relation among the young, violence and the media. It approaches the construction of certain kinds of youngsters as "social monsters" and, therefore, stigmatized by means of communication as socially undesired youngsters by means of the analysis of secondary education students that had their AUGE in the so called "revolución pinguina", which has raised the discussion of public opinion about the inequality and unfairness that exist in Chilean education. It highlights the means of communication role, particularly the one of the press and television, in the construction of an imaginary of the young as "violent youngsters" and it also does a brief interpreting exercise of young violence understood as a "performance" that is used by the means to sell and increase their audience.

\section{Keywords}

Youth and violence. Means of Communication. Performative violence.

\section{Jovens, violência e meios de comunicação}

\section{Resumo}

Este artigo apresenta uma visão da relação entre jovens, violência e meios de comunicação. Aborda a construção de certos tipos de jovens como "monstros sociais" e, portanto, estigmatizados pelos meios de comunicação como jovens não desejados socialmente através da análise das mobilizações dos estudantes secundaristas que tiveram seu auge na denominada "revolución pinguina", que colocou em pauta para a opinião pública as desigualdades e iniqüidades existentes na educação chilena. Destaca-se o papel dos meios de comunicação, particularmente a imprensa escrita e a televisão, na construção de um imaginário dos jovens como "jovens violentos" e se realiza um breve exercício interpretativo da violência juvenil entendida como una "performance" que é utilizada pelos meios para vender e incrementar audiência.

\section{Palavras-chave}

Jovens e violência. Meios de comunicação. Violência performativa. 


\section{Expediente}

A revista E-Compós é a publicação científica em formato eletrônico da Associação Nacional dos Programas de Pós-Graduação em Comunicação (Compós). Lançada em 2004, tem como principal finalidade difundir a produção acadêmica de pesquisadores da área de Comunicação, inseridos em instituições do Brasil e do exterior.
E-COMPÓS I www.e-compos.org.br I E-ISSN 1808-2599

Revista da Associação Nacional dos Programas de Pós-Graduação em Comunicação. Brasília, v.11, n.3, set./dez. 2008

A identificação das edições, a partir de 2008 passa a ser volume anual com três números.

\section{CONSELHO EDITORIAL}

\section{Afonso Albuquerque}

Universidade Federal Fluminense, Brasil

Alberto Carlos Augusto Klein

Universidade Estadual de Londrina, Brasi

Alex Fernando Teixeira Primo

Universidade Federal do Rio Grande do Sul, Brasil

\section{Alfredo Vizeu}

Universidade Federal de Pernambuco, Brasil

Ana Carolina Damboriarena Escosteguy

Pontifícia Universidade Católica do Rio Grande do Sul, Bras

Ana Silvia Lopes Davi Médola

Universidade Estadual Paulista, Brasil

André Luiz Martins Lemos

Universidade Federal da Bahia, Brasil

Ângela Freire Prysthon

Universidade Federal de Pernambuco, Brasil

Antônio Fausto Neto

Universidade do Vale do Rio dos Sinos, Brasil

Antonio Carlos Hohlfeldt

Pontifícia Universidade Católica do Rio Grande do Sul, Brasil

Arlindo Ribeiro Machado

Universidade de São Paulo, Brasil

César Geraldo Guimarães

Universidade Federal de Minas Gerais, Brasil

Cristiane Freitas Gutfreind

Pontifícia Universidade Católica do Rio Grande do Sul, Brasil

Denilson Lopes

Universidade Federal do Rio de Janeiro, Brasil

Eduardo Peñuela Cañizal

Universidade Paulista, Brasi

Erick Felinto de Oliveira

Universidade do Estado do Rio de Janeiro, Brasil

Francisco Menezes Martins

Universidade Tuiuti do Paraná, Brasil

Gelson Santana

Universidade Anhembi/Morumbi, Brasi

Hector Ospina

Universidad de Manizales, Colômbia

leda Tucherman

Universidade Federal do Rio de Janeiro, Brasil

Itania Maria Mota Gomes

Universidade Federal da Bahia, Brasil

Janice Caiafa

Universidade Federal do Rio de Janeiro, Brasil

Jeder Silveira Janotti Junior

Universidade Federal da Bahia, Brasil

\section{João Freire Filho}

Universidade Federal do Rio de Janeiro, Brasil

John DH Downing

University of Texas at Austin, Estados Unidos

José Luiz Aidar Prado

Pontifícia Universidade Católica de São Paulo, Brasil

José Luiz Warren Jardim Gomes Braga

Universidade do Vale do Rio dos Sinos, Brasil

Juremir Machado da Silva

Pontifícia Universidade Católica do Rio Grande do Sul, Brasil

Lorraine Leu

University of Bristol, Grã-Bretanha

Luiz Claudio Martino

Universidade de Brasília, Brasil

Maria Immacolata Vassallo de Lopes

Universidade de São Paulo, Brasil

Maria Lucia Santaella

Pontifícia Universidade Católica de São Paulo, Brasil

Mauro Pereira Porto

Tulane University, Estados Unidos

Muniz Sodre de Araujo Cabral

Universidade Federal do Rio de Janeiro, Brasil

Nilda Aparecida Jacks

Universidade Federal do Rio Grande do Sul, Brasil

Paulo Roberto Gibaldi Vaz

Universidade Federal do Rio de Janeiro, Brasil

Renato Cordeiro Gomes

Pontifícia Universidade Católica do Rio de Janeiro, Brasil

Ronaldo George Hela

Universidade do Estado do Rio de Janeiro, Brasil

Rosana de Lima Soares

Universidade de São Paulo, Brasil

Rossana Reguillo

Instituto Tecnológico y de Estudios Superiores do Occidente, México

Rousiley Celi Moreira Maia

Universidade Federal de Minas Gerais, Brasil

Sebastião Carlos de Morais Squirra

Universidade Metodista de São Paulo, Brasi

Simone Maria Andrade Pereira de Sá

Universidade Federal Fluminense, Brasil

Suzete Venturelli

Universidade de Brasília, Brasil

Valério Cruz Brittos

Universidade do Vale do Rio dos Sinos, Brasil

Veneza Mayora Ronsini

Universidade Federal de Santa Maria, Brasil

Vera Regina Veiga França

Universidade Federal de Minas Gerais, Brasil
COMISSÃO EDITORIAL

Ana Gruszynski I Universidade Federal do Rio Grande do Sul, Brasil

Rose Melo Rocha I Escola Superior de Propaganda e Marketing, Brasil

\section{CONSULTORES AD HOC}

Alexsandro Galeno Araújo Dantas I Universidade Federal do Rio Grande do Norte, Brasil Isaltina Gomes I Universidade Federal de Pernambuco, Bras João Luís Anzanello Carrascoza I Escola Superior de Propaganda e Marketing, Brasil Malena Segura Contrera I Universidade Paulista, Brasil

Marcia Benetti I Universidade Federal do Rio Grande do Sul, Brasi

Maria Aparecida Baccega I Universidade de São Paulo, Bras

Vander Casaqui I Escola Superior de Propaganda e Marketing, Brasil

Virginia Pradelina da Silveira Fonseca I Universidade Federal do Rio Grande do Sul, Brasil

REVISÃO DE TEXTO E TRADUÇÃo I Everton Cardoso

ASSISTÊNCIA EDITORIAL E EDITORAÇÃO ELETRÔNICA I Raquel Castedo
COMPós I www.compos.org.br

Associação Nacional dos Programas de Pós-Graduação em Comunicação

Presidente

Erick Felinto de Oliveira

Universidade do Estado do Rio de Janeiro, Brasil erickfelinto@uol.com.br

Vice-presidente

Ana Silvia Lopes Davi Médola

Universidade Estadual Paulista, Brasil

asilvia@faac.unesp.br

Secretária-Geral

Denize Correa Araújo

Universidade Tuiuti do Paraná, Brasil

denizearaujo@hotmail.com 